\title{
Immune response in Santa Inês sheep during Fasciola hepatica infection
}

\section{Resposta imune em ovinos da raça Santa Inês durante a infecção por Fasciola hepatica}

\author{
Eveline Albuquerque Mendes ${ }^{1}$; Cíntia Aparecida de Jesus Pereira²; \\ Walter dos Santos Lima*
}

\section{Highlights}

The IgG antibody response was more marked at 60 days than at $210 \mathrm{dpi}$.

60 dpi was characterized by production of IFN- $\gamma$ and IL-10.

Modulation of the response was seen at $210 \mathrm{dpi}$, with IL-10 and IL-4 over IFN-Y.

\section{Abstract}

In the present study, we describe the proliferative response and the IFN-y, IL-10, IL-4 cytokine expression profiles in peripheral blood, and IgG production, after the experimental infection of Santa Inês sheep with 250 Fasciola hepatica metacercariae that were evaluated at 60 and 210 days post-infection(dpi). The cytokine expression profile at $60 \mathrm{dpi}$ was characterized by the production of IFN- $\gamma$ and IL-10, which is indicative of an initial mixed Th1/Th2 response. The modulation of the response occurred at $210 \mathrm{dpi}$ with a predominance of IL-10 and IL-4 over IFN-y. Mononuclear cells from peripheral blood stimulated with $F$. hepatica antigen exhibited proliferative capacity at $60 \mathrm{dpi}$, whereas the response was consistent with modulation from Th1 to Th2 in the chronic phase. The IgG antibody response was more marked at 60 days than at $210 \mathrm{dpi}$, confirming the mixed-response profile. The late modulation of the $T$ lymphocyte response in association with the predominance of IL-10 and IL-4 at 210 dpi suggests the involvement of these cytokines after the establishment of the parasites in the bile ducts. The transition from a mixed to a regulatory response in the chronic phase was also accompanied by a reduced number of eggs per gram of feces.

Key words: Trematode. Small ruminants. Immunomodulation. Cytokine.

\section{Resumo}

No presente estudo, observou-se a resposta proliferativa e os perfis de expressão de citocinas IFN-Y, IL10, IL-4 no sangue periférico, e a produção de IgG, aos 60 e 210 dias após infecção (dpi) experimental de ovinos Santa Inês com 250 metacercárias de Fasciola hepatica. O perfil de expressão de citocinas aos 60

1 Doctoral Student of the Postgraduate Program in Parasitology, Instituto de Ciências Biológicas, Universidade Federal de Minas Gerais, ICB, UFMG, Belo Horizonte, MG, Brasil. E-mail: eveonlinne@yahoo.com.br

2 Profs. Drs., Laboratório de Helmintologia Veterinária, Departamento de Parasitologia, ICB, UFMG, Belo Horizonte, MG, Brasil. E-mail: cintiajp@icb.ufmg.br; wlima@icb.ufmg.br

* Author for correspondence

Received: Mar. 10, 2021 - Approved: June 28, 2021 
dpi foi caracterizado pela produção de IFN-y e IL-10, o que é indicativo de uma resposta mista inicial Th1/ Th2. A modulação da resposta ocorreu aos 210 dpi, com predominância de IL-10 e IL-4 sobre IFN-ץ. As células mononucleares do sangue periférico estimuladas com antígeno total de $F$. hepatica adulta exibiram capacidade proliferativa aos 60 dpi, enquanto a resposta foi consistente com uma modulação de Th1 para Th2 na fase crônica. A resposta do anticorpo lgG foi maior aos 60 dpi do que aos 210 dpi. A modulação tardia da resposta dos linfócitos T em associação com a predominância de IL-10 e IL-4 aos 210 dpi sugere o envolvimento dessas citocinas após o estabelecimento dos parasitos nos ductos biliares. A transição de uma resposta mista para uma resposta com pefil regulador na fase crônica também foi acompanhada por redução dos ovos por grama de fezes.

Palavras-chave: Trematódeo. Pequenos ruminantes. Imunomodulação. Citocina.

\section{Introduction}

Fasciola hepatica is a parasite of the hepatic ducts that causes fascioliasis invarious vertebrate host species. It is among the most important trematode parasites in domestic ruminants (Dracz \& Lima, 2014). The economic damage to livestock production is attributed the condemnation of livers in slaughter and processing facilities, growth retardation in young animals, decreased milk, meat and wool productivity and quality, secondary bacterial infections, reduced fertility, high costs of anthelmintics used for infection control, and increased mortality rates (Lima, Soares, Barçante, Guimarães, \& Barçante, 2009; Pereira et al., 2016). In human medicine, fascioliasis is important because it is a zoonosis that has been declared a public health problem by the World Health Organization (WHO), especially in endemic areas, with an estimated 17 million individuals infected worldwide and 180 million at risk of infection (Dalton, Robinson, Mulcahy, O'Neill, \& Donnelly, 2013). Fascioliasis has a high economic impact within veterinary medicine, with more than 700 million livestock at risk of infection and economic losses between million and billion US dollars per year per year (Dalton et al., 2013; Beesley, Williams, Paterson, \& Hodgkinson, 2017).
This parasite has wide geographical distribution around the world and a large number of host species, especially sheep, cattle and goats, but also buffalos, rabbits, rats, mice, capybaras, pigs, alpacas, llamas, marsupials, non-human primates and even humans. Therefore, great interest in the diverse aspects of parasite-host interactions in the course of infection has arisen (Dracz, Ribeiro, Pereira, \& Lima, 2016). While many host species can be infected by $F$. hepatica, there is great variation in its hosts' degree of susceptibility to infection and ability to acquire resistance to reinfection.

Experimental data have suggested that sheep develop little or no immune resistance to F. hepatica (Flynn \& Musah-Eroje, 2020). These hosts often die from acute fascioliasis, whereas in other hosts, the parasites can remain in the organism for long periods (Dalton et al., 2013). In Brazil, where fascioliasis is currently increasing (Lima et al., 2009), Santa Inês sheep are reared in endemic areas, thus drawing attention to parasitism in these animals. This breed is emerging as an excellent alternative for breeders who seek large shorthaired productive animals that are perfectly adapted to environmental conditions. In addition to these characteristics, Santa Inês sheep are highly fertile, prolific and precocious. 
Overall, the immune response mechanisms of domestic ruminants include early-onset eosinophilia, macrophage activation, antibody-dependent cell-mediated cytotoxicity and the action of regulatory cytokines (IL-10 and TGF- $\beta$ ) and Th1 and Th2 cytokines (IFN- $\gamma$ and IL-4, respectively) (Mendes et al., 2013; Ruiz-Campillo et al., 2017; Flynn \& Musah-Eroje, 2020; Vukman, Adams, Metz, Maurer, \& O'Neill, 2013a; Vukman, Adams, \& O'Neill, 2013b; Aldridge \& O’Neill, 2016; Ravida et al., 2016). However, after the initial stages, the parasites develop mechanisms to subvert and modulate the innate immune response and skew it towards an adaptive response characterized by $\mathrm{IL}-4$ production. This modulation of the T-cell response results in the development of the parasite, after which the infection becomes chronic and adult flukes become established in the bile ducts (Dalton et al., 2013; Flynn \& Musah-Eroje, 2020).

In the present study, we evaluated the immune response of Santa Inês sheep in the acute (60 days post-infection, dpi) and chronic (210 dpi) phases of $F$. hepatica infection. For this purpose, the systemic response to infection was assessed through evaluation of IFN-y, IL-10 and IL-4 gene expression, peripheral blood mononuclear cell (PBMC) proliferation and IgG antibody production.

\section{Materials and Methods}

\section{Experimental infection in sheep}

Eight Santa Inês sheep (four males and four females) aged eight months and weighing 33-35 kg were orally inoculated with 250 $F$. hepatica metacercariae (patent number: BR1020120333058) packed in cylindrical tubes. These metacercariae were obtained through experimental infection of Lymnaea (Pseudosuccinea) columella, kept at the Veterinary Helminthology Laboratory, Institute of Biological Sciences (Instituto de Ciências Biológicas, ICB) of the Federal University of Minas Gerais (Universidade Federal de Minas Gerais, UFMG), Brazil. The procedures used in this study had been authorized by UFMG's ethics committee for use of animals [15/2016], these sheep were then identified by earrings and separated on experimental stalls. The control group consisted of four non-infected animals, comprising three males and one female. Feces were collected daily, starting from day 45 post-infection, to determine the prepatent period. After confirmation of the pre-patent period, the collection of feces was monthly to ascertain the degree of infection by counting the eggs per gram of feces (EPG) and to determine the EPG values during the acute and chronic phases. Blood was collected from the jugular vein at $60 \mathrm{dpi}$ and $210 \mathrm{dpi}$.

\section{Preparation of crude Fasciola hepatica antigen}

Ninety-six adult flukes were collected from the bile ducts of the livers of cattle at the time of slaughter in an abattoir. These parasites were washed three times with phosphate-buffered saline (PBS) to remove blood and bile. They were then subjected to mechanical maceration, exposure to five cycles in an ultrasound device at 30 s intervals, and centrifugation at $4,000 \mathrm{~g}$ for $50 \mathrm{~min}$. The supernatant was filtered through a $0.25 \mu \mathrm{m}$ Millex HV filter (Millipore ${ }^{\circledR}$ ) and was stored at $-20{ }^{\circ} \mathrm{C}$. The protein content was determined using a BCA kit (Pierce BCA kit, Pierce, USA). 


\section{PBMC isolation and culture}

A total of $10 \mathrm{~mL}$ of Ficoll-Hypaque solution (Histopaque ${ }^{\circledR}$ 1077, Sigma, USA) was added to $20 \mathrm{~mL}$ of the blood that had been collected. The material was centrifuged at $1.200 \mathrm{~g}$ for $40 \mathrm{~min}$. Cells were collected and resuspended in RPMI medium (Sigma, USA) supplemented with $10 \%$ fetal bovine serum (FBS; Cultilab, Brazil), 3\% $1000 \mathrm{U} / \mathrm{mL}$ penicillin, $1000 \mu \mathrm{g} / \mathrm{mL}$ streptomycin (Invitrogen, USA) and $1.6 \%$ L-glutamine (Synth, Brazil) (Moreau \& Chauvin, 2010). In addition, $2.5 \times 10^{5}$ cells/well were co-incubated with $0.5 \mu \mathrm{g} / \mathrm{mL}$ of crude $F$. hepatica antigen or phytohemagglutinin (PHA) as a positive control, in 96-well microplates for $72 \mathrm{~h}$ at $37^{\circ} \mathrm{C}$, in the presence of $5 \% \mathrm{CO}_{2}$. The negative control consisted of cells that were incubated in the absence of crude antigen or PHA.

\section{Cell proliferation assay}

A 3- (4,5-dimethyl-2-thiazolyl) -2,5diphenyl-2H-tetrazol bromide (MTT) assay was carried out to assess cell proliferation from non-infected and Fasciola hepatica-infected sheep in the acute and chronic phases of infection, as previously described (Moreau, Herve, Yu, \& Alain, 2002). The proliferative response of PBMCs to $F$. hepatica antigens was also determined after stimulation with adult worm crude antigen. Briefly, aliquots of 180 $\mu \mathrm{L}$ of cell suspension in RPMI 1640 medium supplemented with $10 \%$ heat-inactivated fetal calf serum, 1.6\% L-glutamine (Sigma, USA) and $3 \%$ antibiotic-antimycotic (Invitrogen, USA) were cultured in a flat-bottomed 96-well plate, containing $20 \mu \mathrm{L}$ of $25 \mu \mathrm{g} / \mathrm{mL}$ of adult worm crude antigen, for $72 \mathrm{~h}$ in an atmosphere of $5 \% \mathrm{CO}_{2}$ at $37^{\circ} \mathrm{C}$. This step was followed by addition of $20 \mu \mathrm{L}$ of MTT solution ( $5 \mathrm{mg} / \mathrm{mL}$ ) and incubation of the plates for $24 \mathrm{~h}$. After incubation, the supernatant was carefully removed from the wells, followed by addition of $100 \mu \mathrm{L}$ of DMSO, with thorough mixing. Following this, the mean optical density at $570 \mathrm{~nm}$ was determined using an ELISA reader (Molecular Devices, USA). The cell proliferation index of non-stimulated cells was used as a reference value, and percentages of Fasciola crude antigen-stimulated cells were calculated from this value.

\section{Total RNA extraction}

After PBMCs had been stimulated in vitro with crude $F$. hepatica antigen, total RNA was extracted using Trizol $^{\circledR}$ (Invitrogen Life Technologies), by following manufacturer's instructions. The RNA thus isolated was resuspended with $1 \mathrm{~mL}$ of diethylpyrocarbonate (DEPC)-treated water (1 $\mathrm{mL}$ of $0.1 \%$ DEPC per $1000 \mathrm{~mL}$ of sterile distilled water). The RNA concentrations and quality were assessed employing a NanoDrop spectrophotometer (Nanovue Plus ${ }^{\mathrm{TM}}$, GE Healthcare, USA).

\section{Real-time quantitative PCR (qRT-PCR)}

The primer sequences (Table 1) for IFN-y, IL-4, IL-10 and GAPDH gene expression analysis were obtained from Pleasance, Wiedosari, Raadsma, Meeusen and Piedrafita, (2011) or were designed from sequences available from GenBank (www.ncbi.nlm. nih.gov), using the Oligo Explorer software v1.5. The SuperScript ${ }^{\circledR}$ III Platinum $^{\circledR}$ SYBR Green one-step qRT-PCR kit (Invitrogen Life Technologies) was used for qRT-PCR, and the 
amplifications were performed in triplicates. The fluorescence intensity of the qRT-PCR products was measured througt the 7500 RealTime PCR equipment (Applied Biosystems) after each amplification cycle, and probes were then analyzed using the Sequence Detection
Software (SDS) v1.3 (Applied Biosystems). The results are expressed as $2^{-(\Delta \Delta C t)}$, using the respective negative control samples (from cells incubated in the absence of crude $F$. hepatica antigen) for calibration.

\section{Table 1}

Primers used for analysis on IFN-y, IL-4 and IL-10 gene expression in peripheral blood mononuclear cells from sheep experimentally infected with Fasciola hepatica

\begin{tabular}{|c|c|c|}
\hline Gene & Sequences & Accession no. \\
\hline \multirow{2}{*}{ IFN-Y } & Forward - 3' TGATTCAAATTCCGGTGGATG 5' & \multirow{2}{*}{ NM_001009803.1 } \\
\hline & Reverse - 3' TTCATTGATGGCTTTGCGC 5' & \\
\hline \multirow{2}{*}{$\mathrm{IL}-4$} & Forward - 3' GGGCGGACTTGACAGGAA 5' & \multirow{2}{*}{ NM_001009313.2 } \\
\hline & Reverse - 3'ACTCGTCTTGGCTTCATTCACA 5' & \\
\hline \multirow{2}{*}{ GAPDH } & Forward - 3' TGACCTTCACTACATGGTCTAC 5' & \multirow{2}{*}{ NM_001190390.1 } \\
\hline & Reverse - 3' TTCCATTGATGACGAGCTTCC 5' & \\
\hline
\end{tabular}

Characterization of IgG antibody production using ELISA

Serum was obtained by collecting 5 $\mathrm{mL}$ of blood in the absence of anticoagulant and allowing it to clot for $30 \mathrm{~min}$ at $25^{\circ} \mathrm{C}$. The material was then centrifuged at $100 \mathrm{~g}$ for $15 \mathrm{~min}$, and the supernatant was collected. ELISA reactions were performed in 96-well polyethylene microplates (Falcon ${ }^{\circledR}, \mathrm{BD}$ Lab, USA). Each well was sensitized with $1 \mu \mathrm{g}$ of crude $F$. hepatica antigen diluted in $50 \mu \mathrm{L}$ of Milli-Q water, and the plate was incubated overnight at $4^{\circ} \mathrm{C}$.

After sensitization, the wells were blocked with 5\% FBS-PBS and were incubated for 1 h at $37^{\circ} \mathrm{C}$. Serum samples from infected or control animals were diluted 1:500 with $0.05 \%$
Tween 20-PBS, and were then added to the respective wells and incubated for $1 \mathrm{~h}$ at $37^{\circ} \mathrm{C}$. After three washing steps using $0.05 \%$ Tween 20-PBS, specific peroxidase-labeled sheep anti-IgG antibodies (Bethyl Laboratories, USA) were added to each well at a dilution of 1:2000, and the plate was incubated for $1 \mathrm{~h}$ at $37^{\circ} \mathrm{C}$.

After three washing steps using 0.05\% Tween 20-PBS, the reaction was developed with a chromogenic substrate containing hydrogen peroxide (Sigma, USA) and o-phenylenediamine (OPD; Sigma, USA) in citrate buffer. The optical density of each well was measured in a microplate reader (SpectraMax, Molecular Devices, USA) at a wavelength of $492 \mathrm{~nm}$. 


\section{Statistical analysis}

The data were tested for Gaussian distribution employing the KolmogorovSmirnov test. For nonparametric data, the $t$ and Mann-Whitney $U$ tests were used for comparisons between pairs of groups. Comparisons of three or more groups were performed through analysis of variance (ANOVA) followed by Tukey's test for parametric data or the Kruskal-Wallis test followed by Dunn's test for nonparametric data. The maximum residual test (Grubb's test) was used to detect possible outliers. Spearman's correlation was also computed to investigate associations between IL-4 and IL-10 expression levels. All statistics were calculated using Prism 5.0 for Windows (GraphPad Software Inc., USA). Differences were considered statistically significant at $p \leq$ 0.05 .

\section{Results and Discussion}

Presence of infection was confirmed through detection of $F$. hepatica eggs in the feces of infected sheep. The prepatent period was determined to be $58 \mathrm{dpi}$ and the initial mean egg concentration was $19.12 \pm$
4.29 EPG. At $60 \mathrm{dpi}$, the mean EPG value was $22.75 \pm 6.78 \mathrm{EPG}$, whereas at $210 \mathrm{dpi}$, seven animals were negative for fecal eggs and one exhibited 32 EPG. The difference between the EPG concentrations at $60 \mathrm{dpi}$ and 210 dpi was significant $(p=0.0116)$ (Figure 1).

\section{IFN-y, IL-4 and IL-10 gene expression}

The contribution of the modulatory Th1 and Th2 response was evaluated by measuring the relative expressions of IFN- $y$, IL-10 and IL-4 genes in the infected and control sheep. The relationships between cytokine expression profiles were assessed by calculating the IL-10/ IFN- $y$ and IL-4/IFN- $y$ ratios and the correlation between IL-4 and IL-10, as shown in Figures 2a and $2 b$, and 3 , respectively. In all comparisons between expression levels, the ratios of the infected group at $60 \mathrm{dpi}$ were similar to those of the control group. At $210 \mathrm{dpi}$, the IL-4/IFN-Y ratio (Figure 2a) in the infected animals was 5.3 times higher than in the control animals ( $p=0.0485$ ) and 4.4 times higher than in the infected animals at $60 \mathrm{dpi}(\mathrm{p}=0.0457)$, thus indicating that Th2 response predominated over Th1 response in the chronic phase of infection. 


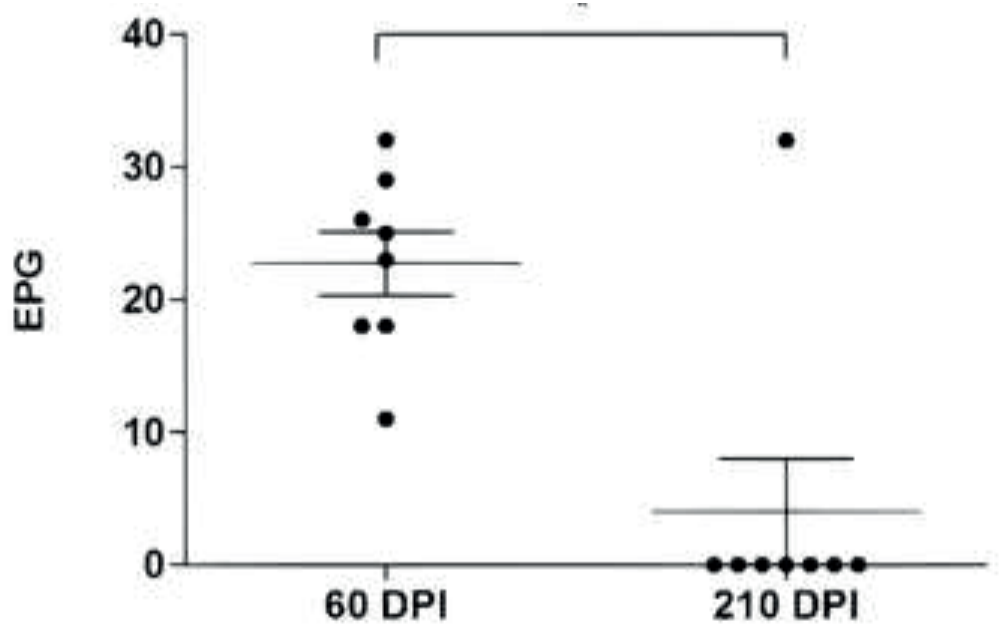

Figure 1. Number of eggs per gram of feces (EPG) among sheep experimentally infected with F. hepatica at $60(60 \mathrm{DPI})$ and 210 days (210 DPI) post-infection. Significant differences are indicated on the graphs in terms of their significant $P$ values $\left({ }^{*} p<0.05\right)$.
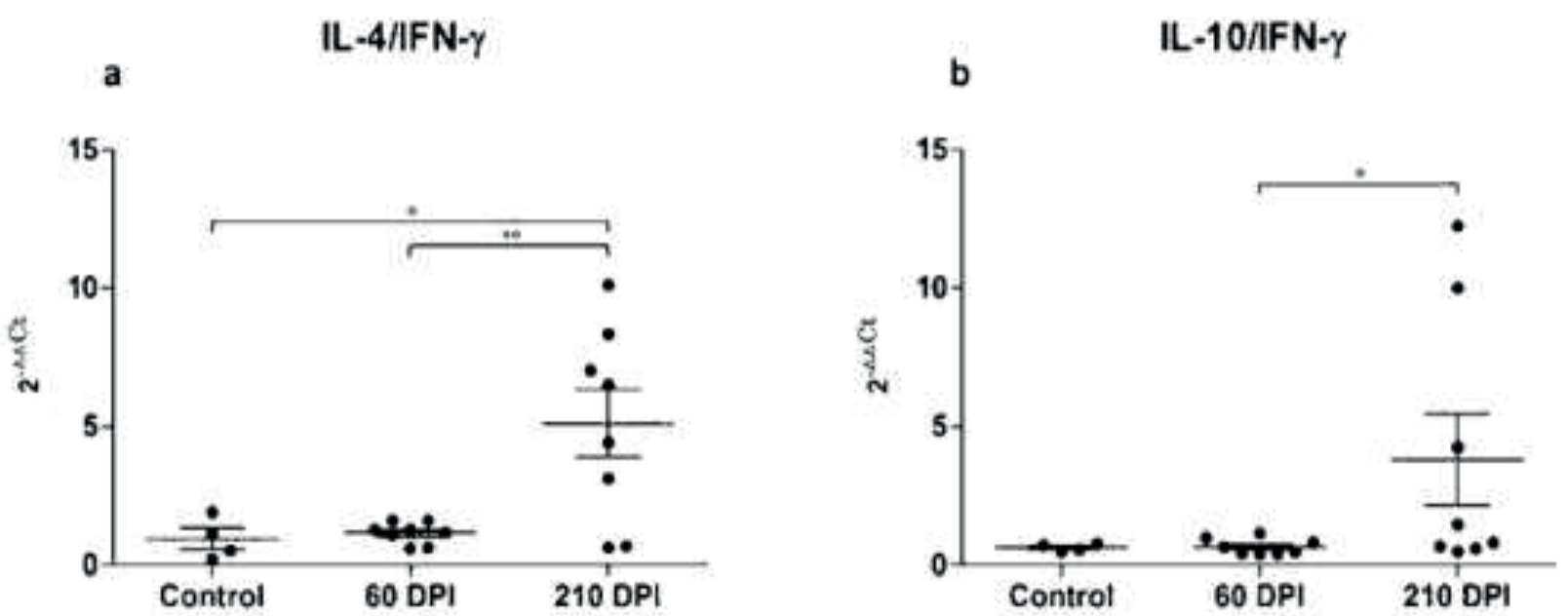

Figure 2. Ratio between the relative expressions of IL-4/IFN-y (a) and IL-10/IFN-y (b) between infected animals and controls at 60 and 210 days after infection with $F$. hepatica. Values represent mean \pm SD. Significant differences are indicated on the graphs in terms of their significant $P$ values $\left({ }^{*} p<0.05 ;{ }^{* *} p<0.01\right)$.

The IL-10/IFN-Y ratio at $210 \mathrm{dpi}$ was 5.2 times higher than at $60 \mathrm{dpi}(\mathrm{p}=$ 0.0499) (Figure 2b), thus suggesting that an immunomodulatory response had occurred and was inversely proportional to the Th1 response. A positive correlation $(r=0.9810$; $\mathrm{p}<0.0001)$ between IL-4 and IL-10 was observed at $210 \mathrm{dpi}$, which suggested that synergy existed between these cytokines in the chronic phase, thereby opposing a Th1 response (Figure 3). 


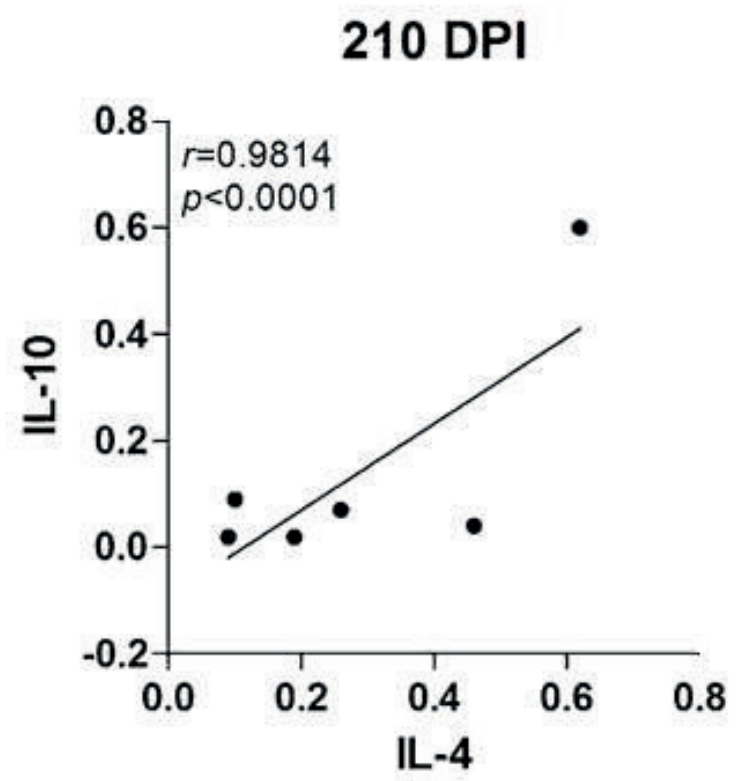

Figure 3. Correlation between the expressions of IL-4 and IL-10 at 210 days after infection with $F$. hepatica. Spearman's correlation indexes ( $r$ and $p$-values) are shown on the graphs. Connecting lines illustrate positive and negative correlation indexes.

\section{PBMC proliferation}

PBMCs collected at $60 \mathrm{dpi}$ from infected sheep and incubated with crude F. hepatica antigen exhibited proliferative capacity in the acute phase of infection.
The differences were significant concerning PBMCs from non-infected sheep $(p=0.0205)$ (Figure 4). At $210 \mathrm{dpi}$, there were no differences in the proliferation profile of PBMC cultures incubated with crude F. hepatica antigen, between control and infected animals.

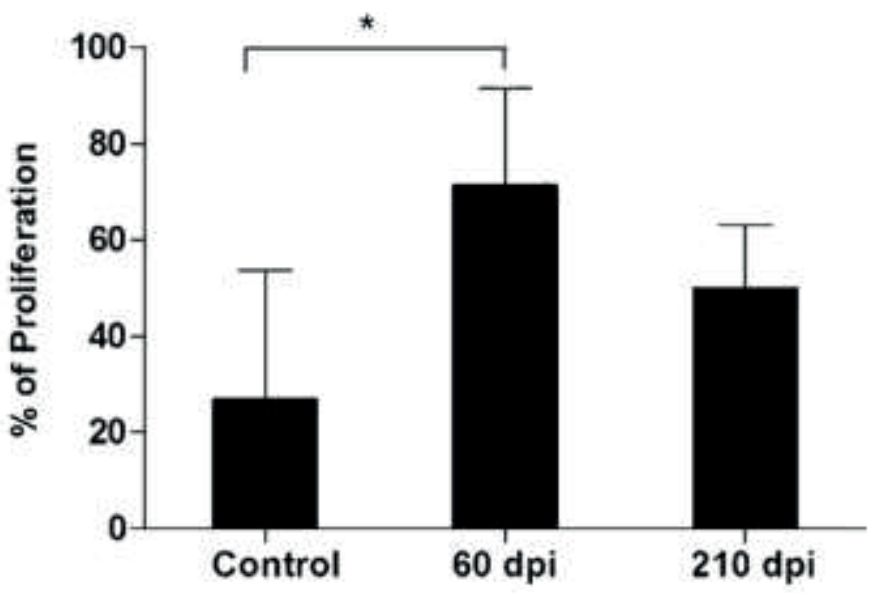

Figure 4. Cell proliferation profile of PBMCs $\left(2 \times 10^{5}\right)$ in Santa Inês sheep experimentally infected with $F$. hepatica and control animals, after culturing with the entire parasite for 72 hours. Antigen at a concentration of $5 \mu \mathrm{g} / \mathrm{ml}$ and PHA at a concentration of $5 \mu \mathrm{g} / \mathrm{mL}$. Values represent mean \pm SD. Significant differences are indicated on the graphs in terms of their significant $P$ values $\left({ }^{*} p<0.05\right)$. 
Characterization of IgG antibody production using ELISA

The means for the control and infected animals differed significantly at $60 \mathrm{dpi}$ ( $\mathrm{p}<$ 0.0001). However, there was no significant difference between the control and infected animals at $210 \mathrm{dpi}(\mathrm{p}=0.0804)$. Comparison of the means within the group of infected animals (60 days vs. 120 days post-infection) also revealed a significant difference $(p<0.0001)$. Furthermore, the IgG levels were significantly higher at $60 \mathrm{dpi}$ (Figure 5).

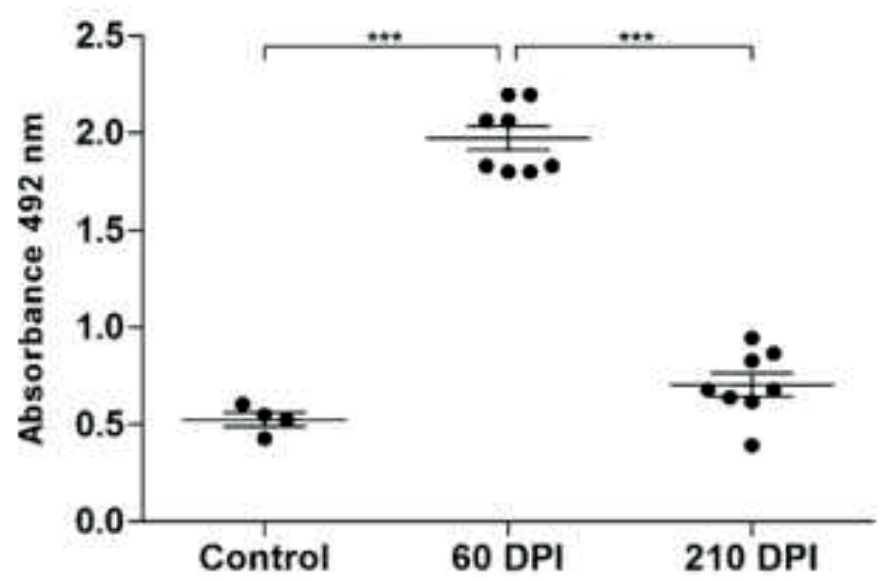

Figure 5. Mean IgG antibody absorbances in serum samples from Santa Inês sheep experimentally infected with $F$. hepatica at 60 (60 DPI) and 210 days (210 DPI) post-infection and in samples from control sheep. Values represent mean \pm SD. Significant differences are indicated on the graphs in terms of their significant $P$ values $\left({ }^{* *} p<0.01\right)$.

Among the commonly cited parasitic infections in ruminants, fascioliasis caused by F. hepatica stands out as one of the most important infections in sheep (Furst, Duthaler, Sripa, Utzinger, \& Keiser, 2012; Rojo-Vazquez, Meana, Valcarcel, \& Martinez-Valladares, 2012). Unlike cattle, sheep have less natural resistance to $F$. hepatica due to lower ability to limit and repair tissue damage and due to lower parasite control via calcification of the bile ducts (Dalton et al., 2013). The T cell response to $F$. hepatica in cattle is predominantly a Th2type immune response, which is characterized by upregulation of IL-4 and downregulation of IFN-Y (Mendes et al., 2013).
In sheep, resistance to Fasciola sp. has been observed in some breeds. The $T$ cell response in resistant breeds, such as Indonesian Thin-Tail (ITT) sheep, is a Th1-type immune response, with predominant IFN-Y production. This indicates that protection against Fasciola sp. is associated with Th1 cytokines (Flynn \& Musah-Eroje, 2020; Moreau \& Chauvin, 2010; Zhang, Moreau, Hope, Howard, Huang, \& Chauvin, 2005). In an infection with $F$. hepatica, the initial Th1 response can act against the parasite within the peritoneal cavity and during its migration through the hepatic parenchyma (Flynn \& Musah-Eroje, 2020). However, the parasite 
develops evasion mechanisms and modulates the host response, which is highly biased towards Th2 in the chronic phase (Moreau \& Chauvin, 2010; Pleasance et al., 2011; Flynn \& Musah-Eroje, 2020). Sheep that are susceptible to $F$. hepatica then develop a mixed Th1/Th2 response, initially characterized by production of IFN-y and IL-10 (Zhang et al., 2005; Flynn \& Musah-Eroje, 2020).

The present study was the first to characterize the expression of the cytokines IFN- $\gamma$, IL-4 and IL-10 in PBMCs, the involvement of IgGantibodies and the proliferative response in Santa Inês sheep, in both the acute and the chronic phases of experimental F. hepatica infection. The systemic cytokine expression profiles of control and infected sheep that were observed in the present study suggest that one of the parasite escape mechanisms involves modulation of the Th1 response through mediation of predominance of IL-10 and IL-4 over IFN-y in the chronic phase (210 dpi).

According to Zhang et al. (2005), the response of susceptible sheep is initially characterized by production of IFN- $Y$ and IL10. Those authors showed that the expression of these cytokines in PBMC cultures from sheep infected with $F$. hepatica was balanced, such that IL-10 production increased in the initial phase and was then sustained during the chronic phase of infection. In the same study, $\mathrm{IL}-10$ production remained constant in the initial weeks of infection and then increased concerning IFN- $y$ over the next eight weeks. Thus, the initial response exhibited a Th1/Th0 phenotype, which suggested that delayed modulation of the response to infection occurred.

In the present study, expression of IFN- $y$ at 60 dpi showed that this cytokine was involved in the initial stages of infection, which was thus in agreement with an initial Th1/ Th0-type response. According to Moreau and Chauvin (2010), sheep that are susceptible to F. hepatica exhibit a mixed Th1/Th2 response, which is characterized by production of both IFN- $y$ and IL-10 during the initial six weeks post-infection. Production of IFN- $y$ in the initial stages of infection has also been reported in cattle (Flynn \& Mulcahy, 2008) and sheep (Moreau \& Chauvin, 2010)

The increased IL-10 expression levels in the group of infected sheep of the present study at $60 \mathrm{dpi}$, compared with 210 $\mathrm{dpi}$, characterized involvement of IL-10 in the initial stages of infection. However, we also suggest that IL-10 was involved in the later stages of infection, i.e. the chronic phase. This observation is accompanied by the higher IL-10/IFN-y ratio in the chronic phase, i.e. at $210 \mathrm{dpi}$. The almost insignificant difference corroborates the involvement of IL-10 during infection and suggests that there is a sensitive balance between this cytokine and IFN- $\gamma$. IL10 might act on the modulation of IFN- $\mathrm{y}$ and contribute to skewing the response towards a Th2 phenotype. This result suggests that IL-10 has a regulatory role througthout of infection of sheep with F. hepatica. We suggest that, in addition to suppressing the development of Th1 cells, IL-10 limits the magnitude of the Th2 response, as shown by the positive correlation between IL-10 and IL-4 at $210 \mathrm{dpi}$. Flynn and Mulcahy (2008) demonstrated that IL-10 and TGF- $\beta$ had roles about modulation of IFN- $\gamma$ and IL-4. Furthermore, IL-10 and TGF- $\beta$ have been reported to present synergistic action within the local response (hepatic lymph nodes), through upregulating IL-4 and downregulating IFN-Y (Hacariz, Sayers, Flynn, Lejeune, \& Mulcahy, 2009). 
The mechanisms involved in modulation by regulatory $T$ cells (Tregs) via TGF- $\beta$ still need to be determined to infection of Santa Inês sheep. The higher IL-4/IFN-Y ratio at 210 dpi skews the response towards a Th2 phenotype, with predominance of IL-4 in the chronic phase of infection. Furthermore, the IL-4/IFN- $\gamma$ ratio was significantly higher at $210 \mathrm{dpi}$ than at $60 \mathrm{dpi}$. This predominance of IL-4 may be associated with susceptibility of Santa Inês sheep to F. hepatica. A similar result was observed by Pleasance et al. (2011), in an analysis on the ratios of these cytokines. Specifically, those authors observed higher levels of IL-4 relative to IFN- $\gamma$ in the mRNA of Merino sheep that were susceptible to $F$. gigantica, in comparison with ITT sheep that were resistant to F. gigantica and susceptible to $F$. hepatica. According to those authors, these results are consistent with a Th2-type cytokine response that was associated with susceptibility to $F$. hepatica in ITT sheep.

We suggest that IL-4 is initially modulated by the balance between IFN- $\mathrm{Y}$ and IL-10, given that there was no difference in IL-4 levels in our study between the infected and control groups at $60 \mathrm{dpi}$. The results observed for IFN- $\gamma$, IL-10 and IL-4 suggested that IL-10 and IL-4 had regulatory roles in a Th0/Th2 phenotype at $210 \mathrm{dpi}$. In the Santa Inês sheep evaluated in the present study, the responses of these cytokines in PBMCs exhibited mixed modulation from Th1/Th0 to Th0/Th2. This mixed modulation directed towards a prolonged Th1 response was characterized by initial production of IFN- $Y$ and IL-10, which interfered with the Th1/Th2 balance. The predominance of IL-4 and IL-10 over IFN- Y at $210 \mathrm{dpi}$ suggested that modulation of the response occurred after the parasite had become established in the bile ducts.
Occurrence of parasite eggs in feces of all animals was confirmed. The transition from the acute phase to the chronic was detected approximately 58 days post infection. Occurrence of parasite eggs in host feces, which indicates the transition from the acute to the chronic phase (Boray, 1967).

The reduced number of eggs at 210 days post-infection, in association with predominance of IL-10, draws attention to the role of $\mathrm{IL}-10$ in modulation of the response. This finding suggests that parasite development or the parasite burden diminishes in response to IL-10 production. This decrease, in turn, might be responsible for sustained infection and the survival of both the host and the parasite. Hacariz et al. (2009) observed that there was an inverse relationship between IL-10 and parasite burden and EPG at 23 weeks post-infection. Specifically, lower IL10 expression levels correlated with higher parasite burden and EPG values. Presence of parasite eggs in host feces correlated with the transition from the acute to the chronic phase. It was suggested that soluble parasite egg antigens could stimulate production of antiinflammatory or regulatory cytokines, similar to some components of $S$. mansoni eggs. This would be responsible for development of Tregs and production of IL-10 and TGF- $\beta$ (Moxon et al., 2010). The single animal that was positive for fecal eggs at 210 dpi may have been indicative of individual variation among hosts due to physiological differences such as body size, weight and nutritional condition, and to differences in the ability of the host immune system to counteract the infection (Hacariz et al., 2009).

The behaviors of PBMCs from infected sheep in the proliferation assays at $60 \mathrm{dpi}$ and $210 \mathrm{dpi}$ were in agreement with the responses 
observed by other authors (Moreau et al., 2002; Zhang et al., 2005). Specifically, lymphocyte proliferation was observed at $60 \mathrm{dpi}$ as a response to crude $F$. hepatica antigen and PHA mitogen. Studies relating to lymphocyte proliferation have shown that the proliferative capacity of T cells in $F$. hepatica infections is characteristic of the initial stages and that this activity decreases over time (Flynn \& Mulcahy, 2008).

In the present study, the lack of a proliferative response at 210 dpi was similar to findings from previous studies (Flynn \& Mulcahy, 2008). We further observed that IL-10 production was associated with reduced IFN- $Y$ production and with reduction of PBMCs during the chronic phase of $F$. hepatica infection. The above authors also observed that IFN- $\mathrm{y}$ levels increased after IL-10 neutralization in vitro, which was compatible with our observations. Specifically, we observed that PBMCs from infected sheep responded to antigen and PHA mitogen stimulation at $60 \mathrm{dpi}$, which was in agreement with the IFN- $Y_{1}$ IL-10 and IL-4 expression profile at this stage. Flynn and Mulcahy (2008) also showed that PBMCs exhibited reduced IL-4 production during the acute phase, which was modulated by IL-10 and TGF- $\beta$. Thus, we suggest that the IL-10, IL-4 and IFN- $\gamma$ levels observed in the present study can be associated with the proliferative lymphocyte response. This, in turn, can act by producing or inhibiting cytokines that are involved in modulation of the immune and inflammatory responses in sheep.

The results from studying T lymphocyte proliferation have shown that $F$. hepatica antigens exertan immunomodulatory effect on lymphocytes. This, as also observed by Dalton et al. (2013), suggests that this response could be an additional evasion mechanism used by these parasites in sheep. These mechanisms are known to be highly complex and still need to be properly investigated.

The humoral immune response to primary $F$. hepatica infection in Santa Inês sheep was determined in the present study by observing the involvement of $\operatorname{lgG}$ at 60 dpi. Chauvin, Bouvet and Boulard (1995) also evaluated the mechanisms involved in the IgG antibody response during primary infection in sheep, and they found that IgG levels began to increase at two weeks postinfection, continued to increase for up to six weeks and became stable at 12 weeks postinfection. In the present study, the results at 60 dpi and 210 dpi differed significantly and suggested that the humoral host defense mechanism occurred in the initial stages of infection. The reduction that was observed in the chronic phase can be explained by the fact that the parasites seemed to exhibit several different escape mechanisms. One of these mechanisms involved release of parasitederived proteases that cleaved the Fc portions of antibodies and thus prevented antibodydependent cell-mediated cytotoxicity (Moreau \& Chauvin, 2010). These results show that IgG antibodies were participating during the acute phase of infection, thereby lending support to the notion that sheep infected with $F$. hepatica presented a humoral response, among other mechanisms.

The results from the present study contribute towards demonstrating that parasite development is related of factors, such as the vertebrate host species, parasite burden and differences between host breeds. These ultimately influence the response to infection, the pathology of the disease, parasite growth and parasite egg production and excretion into the environment. Modulation mechanisms establish interactions that may 
result in host survival and change the behavior of the parasite, as shown by our observation of seven animals that were negative for fecal eggs at $210 \mathrm{dpi}$. The differences in the pathophysiology of fascioliasis that have been observed between different host species require further investigations to identify the diverse factors involved in the mechanisms that lead to survival of both the host and the parasite, thus enabling sustained infection.

\section{Acknowledgements}

We thank the Research Support Foundation of the State of Minas Gerais (Fundação de Amparo à Pesquisa do Estado de Minas Gerais, FAPEMIG) for its financial support (WSL, grant number 18898 and APQ-01709-18), and the National Council for Scientific and Technological Development (Conselho Nacional de Desenvolvimento Científico e Tecnológico, CNPq) for its financial support (WSL, grant number 480469/2012-1).

\section{References}

Aldridge, A., \& O'Neill, S. M. (2016). Fasciola hepatica tegumental antigens induce anergic-like $\mathrm{T}$ cells via dendritic cells in a mannose receptor dependent manner. European Journal of Immunology, 46(5), 1180-1192. doi: 10.1002/eji.201545905

Beesley, N. J., Williams, D. J. L., Paterson, S., \& Hodgkinson, J. (2017). Fasciola hepatica demonstrates high levels of genetic diversity, a lack of population structure and high gene flow: possible implications for drug resistance. International Journal for Parasitology, 47(1), 11-20. doi:10.1016/j. ijpara.2016.09.007
Boray, J. C. (1967). Studies on experimental infections with Fasciola hepatica, with particular reference to acute fascioliasis in sheep. Annals of Tropical Medicine \& Parasitology, 61(4), 439-450. doi: 10. 1080/00034983.1967.11686513

Chauvin, A., Bouvet, G., \& Boulard, C. (1995). Humoral and cellular immune responses to Fasciola hepatica experimental primary and secondary infection in sheep. International Journal for Parasitology, 25(10), 1227-1241. doi: 10.1016/00207519(95)00039-5

Dalton, J. P., Robinson, M. W., Mulcahy, G., O'Neill, S. M., \& Donnelly, S. (2013). Immunomodulatory molecules of Fasciola hepatica: candidates for both vaccine and immunotherapeutic development. Veterinary Parasitology, 195(3-4), 272285. doi: 10.1016/j.vetpar.2013.04.

Dracz, R. M., \& Lima, W. S. (2014). Autochthonous infection of buffaloes and cattle by Fasciola hepatica in Minas Gerais, Brazil. Revista Brasileira de Parasitologia Veterinária, 23(3), 413-416. doi: 10.1590/ S1984-29612014054

Dracz, R. M., Ribeiro, V. M. A., Pereira, C. A. J., \& Lima, W. S. (2016). Ocorrência de Fasciola hepatica (Linnaeus, 1758) em capivara (Hydrochoerus hydrochaeris) (Linnaeus, 1766) em Minas Gerais, Brasil. Revista Brasileira de Parasitologia Veterinária, 25(3), 364-367. doi: 10.1590/S1984-2961 2016021

Flynn, R. J., \& Mulcahy, G. (2008). The roles of IL10 and TGF-beta in controlling IL-4 and IFNgamma production during experimental Fasciola hepatica infection. International Journal for Parasitology, 38(14), 16731680. doi: 10.1016/j.ijpara.2008.05.008 
Flynn, R. J., \& Musah-Eroje, M. (2020). Evasion of Host Immunity during Fasciola hepatica Infection. In M. Cancela, \& G. Maggioli (Eds.), Fasciola hepatica: Methods and Protocols, Methods in Molecular Biology. (Vol. 2137, pp. 107-115). Recovered from https://doi.org/10.1007/978-1-0716-04 75-5_1, (C) Springer Science Business Media, LLC, part of Springer Nature 2020

Furst, T., Duthaler, U., Sripa, B., Utzinger, J., \& Keiser, J. (2012). Trematode infections: liver and lung flukes. Infectious disease clinics, 26(2), 399-419. doi: 10.1016/j.idc. 2012.03.008

Hacariz, O., Sayers, G., Flynn, R. J., Lejeune, A., \& Mulcahy, G. (2009). IL-10 and TGFbeta1 are associated with variations in fluke burdens following experimental fasciolosis in sheep. Parasite Immunology, 31(10), 613-622. doi: 10.1111/j.1365-30 24.2009.01135.x

Lima, W. dos S., Soares, L. R., Barcante, T. A., Guimaraes, M. P., \& Barcante, J. M. (2009) Occurrence of Fasciola hepatica (Linnaeus, 1758) infection in Brazilian cattle of Minas Gerais, Brazil. Revista Brasileira de Parasitologia Veterinária, 18(2), 27-30. doi: 10.4322/rbpv.01802006

Mendes, E. A., Mendes, T. A. O., Santos, S. L., Menezes-Souza, D., Bartholomeu, D. C., Martins, I. V. F., Silva, L.M., Lima, W. S. (2013). Expression of IL-4, IL-10 and IFNgamma in the liver tissue of cattle that are naturally infected with Fasciola hepatica. Veterinary Parasitology, 195(1-2), 177182. doi: 10. 1016/j.vetpar.2013.03.035

Moreau, E., \& Chauvin, A. (2010). Immunity against helminths: interactions with the host and the intercurrent infections. Journal of Biomedicine and
Biotechnology, 2010 (428593), 1-10. doi: $10.1155 / 2010 / 428593$

Moreau, E., Herve, S., Yu, Z. W., \& Alain, C. (2002). Modulation of sheep lymphocyte responses by Fasciola hepatica excretory-secretory products. Veterinary Parasitology, 108(3), 207-215. doi: 10.10 16/S0304-4017(02)00196-6

Moxon, J. V., Flynn, R. J., Golden, O., Hamilton, J. V., Mulcahy, G., \& Brophy, P. M. (2010). Immune responses directed at egg proteins during experimental infection with the liver fluke Fasciola hepatica. Parasite Immunology, 32(2), 111-124. doi: 10.1111/j.1365-3024.2009.01171.x

Pereira, C. A. J., Oliveira, L. L. S., Coaglio, A. L., Santos, F. S. O., Cezar, R. S. M., Mendes, T., Oliveira F. L. P., Consenza, G. Lima, W. S. (2016). Anti-helminthic activity of Momordica charantia L. against Fasciola hepatica eggs after twelve days of incubation in vitro. Veterinary Parasitology, 228(15), 160-166. doi: 10. 1016/j.vetpar.2016.08.025

Pleasance, J., Wiedosari, E., Raadsma, H. W., Meeusen, E., \& Piedrafita, D. (2011). Resistance to liver fluke infection in the natural sheep host is correlated with a type-1 cytokine response. Parasite Immunology, 33(9), 495-505. doi: 10.11 11/j.1365-3024.2011.01305.x

Ravida, A., Aldridge, A. M., Driessen, N. N., Heus, F. A., Hokke, C. H., \& O'Neill, S. M. (2016). Fasciola hepatica surface coat glycoproteins contain Mannosylated and phosphorylated N-glycans and exhibit immune modulatory properties independent of the mannose receptor. PLOS Neglected Tropical Diseases, 10(4), e0004601. doi: 10.1371/journal.pn td.0004601 
Rojo-Vazquez, F. A., Meana, A., Valcarcel, F., \& Martinez-Valladares, M. (2012). Update on trematode infections in sheep. Veterinary Parasitology, 189(1), 15-38. doi: 10.1016/j. vetpar.2012.03.029

Ruiz-Campillo, M. T., Hernandez, V. M., Escamilla, A., Stevenson, M., Perez, J., Martinez-Moreno, Donnelly, S., Dalton, J. P. \& Cwiklinski, K. (2017). Immune signatures of pathogenesis in the peritoneal compartment during early infection of sheep with Fasciola hepatica. Scientific Reports, 7(2782), 1-14. doi: 10.1038/s41 598-017-03094-0

Vukman, K. V., Adams, P. N., \& O'Neill, S. M. (2013b). Fasciola hepatica tegumental coat antigen suppresses MAPK signalling in dendritic cells and up-regulates the expression of SOCS3. Parasite Immunology, 35(7-8), 234-238. doi: 10. 1111/pim.12033
Vukman, K. V., Adams, P. N., Metz, M., Maurer, M., \& O'Neill, S. M. (2013a). Fasciola hepatica tegumental coat impairs mast cells' ability to drive Th1 immune responses. The Journal of Immunology, 190(6), 28732879. doi: $10.4049 /$ jimmunol. 1203011

Zhang, W. Y., Moreau, E., Hope, J. C., Howard, C. J., Huang, W. Y., \& Chauvin, A. (2005). Fasciola hepatica and Fasciola gigantica: comparison of cellular response to experimental infection in sheep. Experimental Parasitology, 111(3), 154159. doi: 10.1016/j.exppara.2005.06.005 
